\title{
GIANT SYRINGOMA, A RARE CASE
}

\author{
Sandhya Bade1, Sandesh Gawade², Shashank Trivedi ${ }^{3}$
}

${ }^{1}$ Senior Resident, Department of General Surgery, M.I.M.E.R. Medical College, Talegaon D, Pune. ${ }^{2}$ Assistant Professor, Department of General Surgery, M.I.M.E.R. Medical College, Talegaon D, Pune. 3Junior Resident, Department of General Surgery, M.I.M.E.R. Medical College, Talegaon D, Pune.

\section{ABSTRACT}

Chondroid syringomas are rare, benign adnexal tumor of the skin arising from the eccrine and apocrine sweat gland with tumor differentiation in the epithelial and mesenchymal tissues. In 1859, Billroth first described chondroid syringomas as a mixed tumor of the skin due to its resemblance to the benign mixed tumor arising from salivary gland.[1,2] They most commonly occur in the head and neck, although they may be also found in the limbs, trunk, axilla, genitalia. The reported incidence is $<0.01 \%$ of all primary skin tumors. An 80-year-old male patient presented to the surgery clinic with a chief complaint of painless, slow-growing swelling on his right mandible, which gradually developed over the period of 20-25yrs. A single, mobile, firm, nontender, nodular surface with subcutaneous plane mass was located on his mandible, which was $6.5 \mathrm{~cm}$ in diameter. The mass was surgically excised and sent for the histopathological evaluation. The results of biopsy confirmed the diagnosis of chondroid syringoma and showed no evidence of malignancy. In this article, we present a case of giant chondroid syringoma over right mandible in the light of literature review.

\section{KEYWORDS}

Giant, Syringoma, Chondroid.

HOW TO CITE THIS ARTICLE: Bade S, Gawade S, Trivedi S. “Giant syringoma, a rare case.” Journal of Evolution of Medical and Dental Sciences 2015; Vol. 4, Issue 104, December 28; Page: 16971-16974, D0I: 10.14260/jemds/2015/2562

\section{INTRODUCTION}

Chondroid syringomas are rare skin adnexal tumor, which can have either a benign or malignant behavior. In 1859, Billroth first described chondroid syringomas as a mixed tumor of the skin due to its resemblance to the benign mixed tumor arising from salivary gland.[1,2] The term 'chondroid syringoma' was first used by Hirsch and Helwig in 1961 to describe this sweat gland tumor, because of the presence of sweat gland element which is set in a cartilaginous stroma. [3] Chondroid syringomas most commonly occur in the head and neck region with a size ranging from $2 \mathrm{~mm}$ to $>1 \mathrm{~cm}$ and usually present with solitary, solid, nontender, subcutaneous or intracutaneous nodule.[4,5] The presentation of chondroid syringomas in other areas of the body is unusual.[6] They often affect middle-aged to elderly patients with a male-to-female ratio of $2: 1,[5,7,8]$ Due to the presence of both epithelial and mesenchymal components, chondroid syringomas was used to be formerly called as a mixed tumor of the skin. [9] Due to its nonspecific presentation, diagnosis is usually made by histopathologic studies.[10] However, chondroid syringomas can be diagnosed using fine needle aspiration cytology.[9] Total surgical excision is the mainstay of treatment for benign chondroid syringoma. Although chondroid syringoma is a benign tumor, malignant form has rarely been reported; therefore, patients are recommended to have regular follow-up after surgery.[11]

In this paper, we report a rare case of a giant chondroid syringoma located over right mandible of an 80-year-old male patient.

\section{CASE REPORT}

An 80-year-old male patient was admitted in general surgery ward with complaints of painless, slowly growing mass over his right mandible which gradually developed over a course of 25 years. [Figure 1,2].

Financial or Other, Competing Interest: None.

Submission 02-12-2015, Peer Review 03-12-2015,

Acceptance 22-12-2015, Published 29-12-2015.

Corresponding Author:

Dr. Sandesh Gawade,

F-702, Phase II,

Celestial City, Ravet,

Pune-412101.

E-mail: drsandesh23@gmail.com

DOI:10.14260/jemds/2015/2562
Patient did not take any kind of treatment for the same. On physical examination there was a solitary, nontender, firm, mobile, nodular surface, subcutaneous mass located over right mandible, which was $6.5 \mathrm{~cm}$ in diameter.

There was no satellite nodule or palpable regional lymph node and systemic examination was within normal limit. Laboratory tests including complete blood count, liver function tests, renal function tests and erythrocyte sedimentation rate were within normal limits with the possible diagnosis of large sebaceous cyst, lipoma and dermatofibrosarcoma, the tumor was surgically excised and sent for the histopathological evaluation. Excised mass was free from underlying structure, well encapsulated [Figure 3]. Postoperative recovery uneventful. Followup at day $25^{\text {th }}$ wound healed well and scar is healthy.

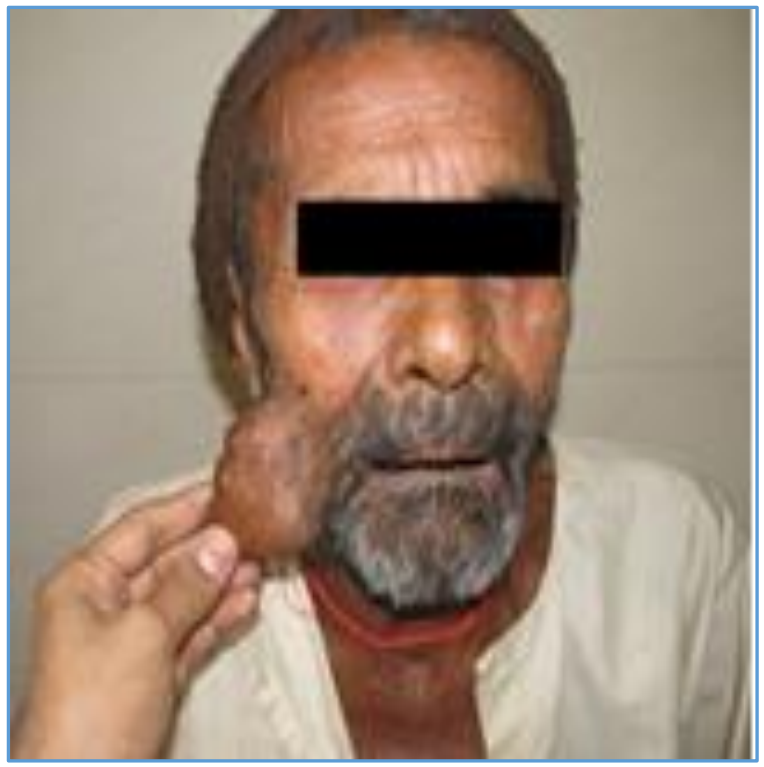

Fig.1 : A nontender, firm, nodular surface, mobile, subcutaneous mass over right mandible. Front View 


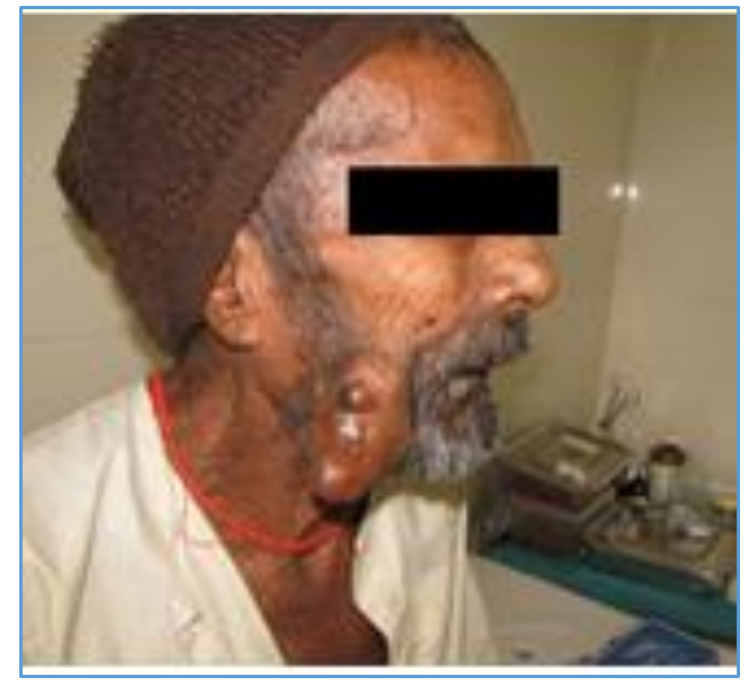

Fig.2: A nontender, firm, nodular surface, mobile, subcutaneous mass over right mandible. Lateral View

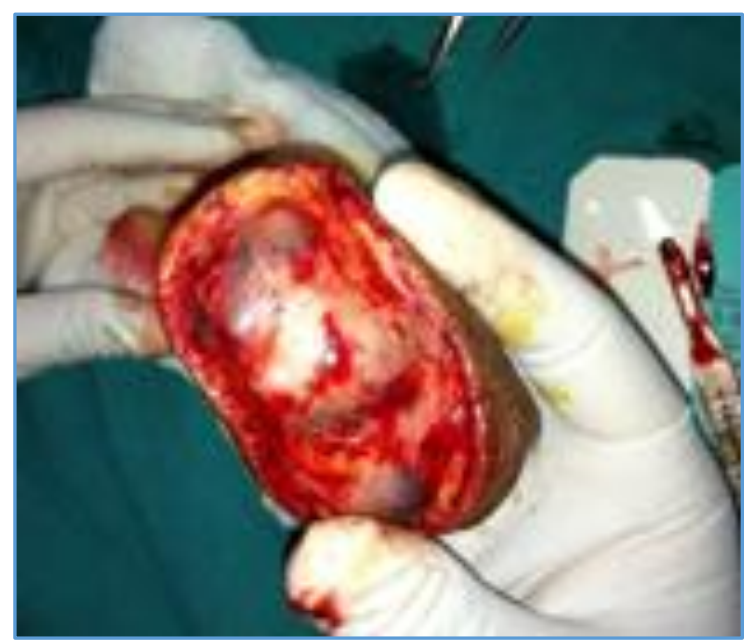

Fig. 3: Excised mass is well encapsulated, free from underlying structure

Histopathological examination revealed following findings......

a. Macroscopic examination showed skin covered mass measuring $7 / 6 / 4 \mathrm{~cm}$. Cut section-gray white in colour focal areas of congestion and haemorrhage seen [Figure 4, 5].

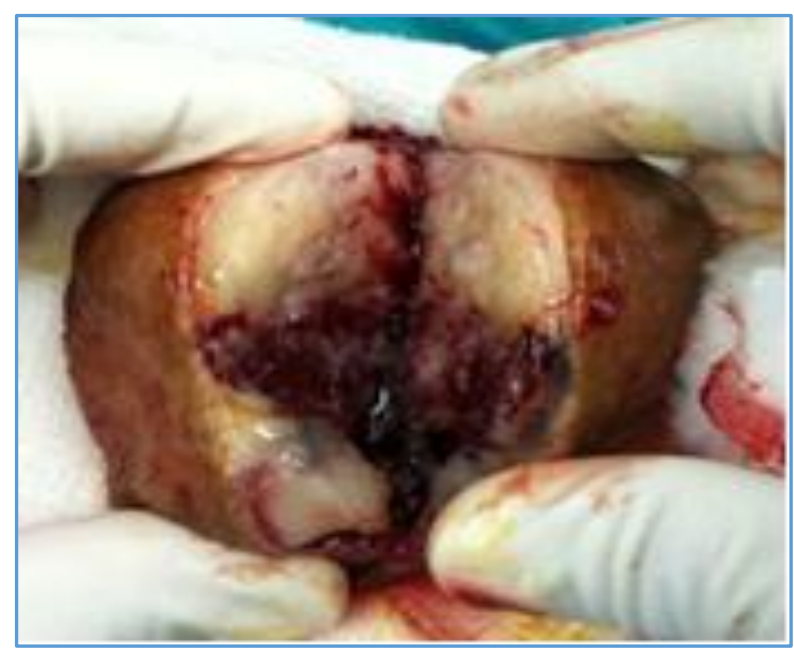

Fig. 4

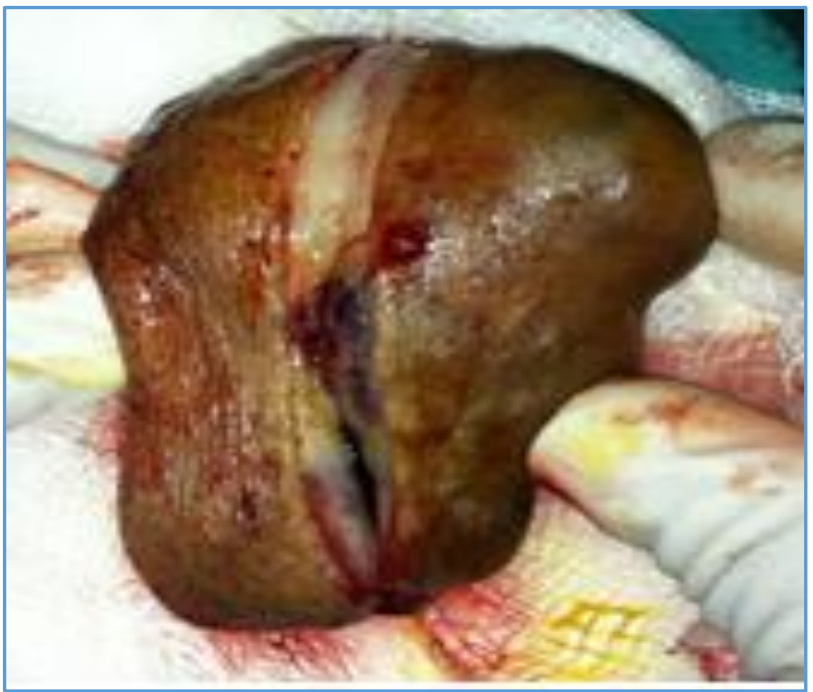

Fig. 5

b. Microscopic findings- Section shows stratified squamous lining epithelium beneath which in the dermis is seen well circumscribed tumor mass composed of epithelial and mesenchymal element. The epithelial element shows benign epithelial cells arranged in solid chords and in ductural pattern. The stroma appears chondromyxoid. Many congested vessels seen [Figure 6 \& 7].

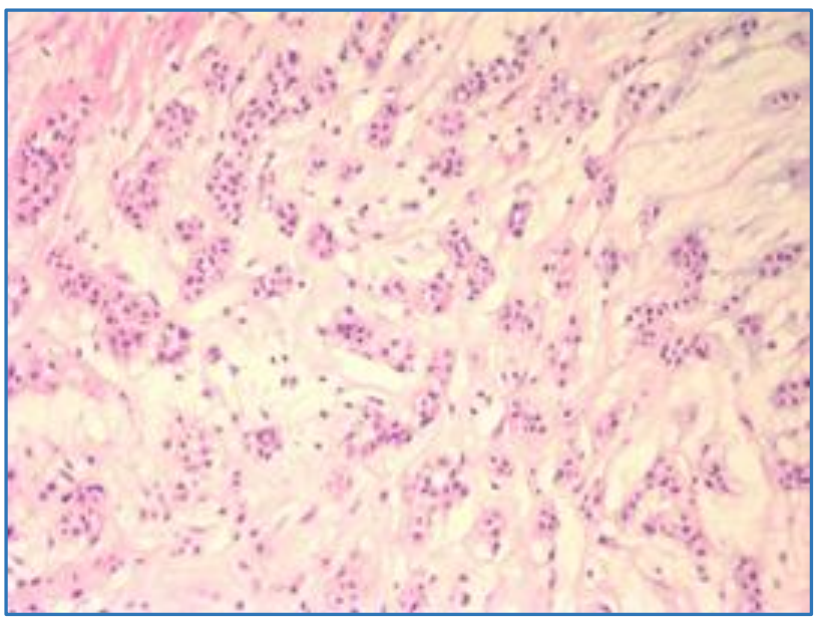

Fig. 6

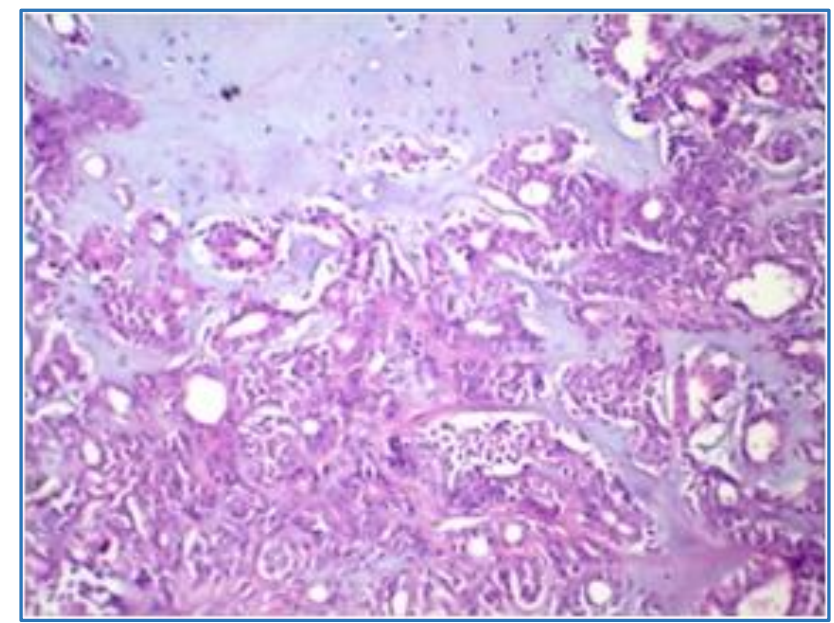

Fig. 7 


\section{DISCUSSION}

Chondroid syringoma is a skin appendage tumor, histopathologically similar to the mixed tumor (pleomorphic adenoma) of the salivary gland. Hirsch and Helwig..[4] in 1961 introduced the term 'chondroid syringoma' to describe this tumor characterized by the presence of sweat gland elements within a cartilaginous stroma. They account for $<0.01 \%$ of all primary skin tumors. Chondroid syringoma generally presents as a slow growing, solid, painless, subcutaneous or intradermal nodule in the head and neck region, most commonly followed by nose, cheeks, upper lip, scalp, forehead, and chin region, which most often affects elderly and middle aged men.[6,10,11,12] Tumor size may range from $2 \mathrm{~mm}$ to $>1 \mathrm{~cm} .[4,5,7,8]$ Chondroid syringoma is a benign lesion in most of the cases and recurrence is uncommon.[13] However, malignant forms of chondroid syringoma has rarely been reported. ${ }^{[12,14]}$ Malignant forms of chondroid syringoma are more common in women and predominantly affects trunk and extremities.[6,11,14] Malignant tumors are usually larger than $3 \mathrm{~cm}$ in size; however, benign tumor measured $10 \mathrm{~cm}$ may also be present.[15]

Analysis of the reported cases showed that the mean age of the patients at the time of diagnosis was 48.3 years (range 13-84 years). The benign tumor tends to occurs mainly in the head and neck ( $80 \%$ in head and neck, $10 \%$ in limbs and $10 \%$ in trunk), while its malignant counterpart tends to affect limbs mostly $61 \%$ in limbs, $17 \%$ in trunk, $22 \%$ in head and neck).[3,16] The female-to-male ratios are $2: 7$ in benign tumor and $3: 2$ in its malignant counterpart.[3] Giant chondroid syringoma also occur at unusual sites such as axilla..17] arm. ${ }^{[2]}$ and shoulder.[18]

Chondroid syringoma does not have characteristic diagnostic clinical features, thus the diagnosis of chondroid syringoma is made by histopathologic studies.[10,14] Chondroid syringoma may be confused clinically with epidermal cyst, dermatofibroma, pilomatricoma, neurofibroma, histiocytoma, seborrheic keratosis, calcifying epithelioma and basal cell carcinoma.[6,12,14]

Histologically, a wide variety of structures may be found in chondroid syringoma of skin. Hirsch and Helwig.[3] proposed the following five histological criteria for diagnosis.(1) Nests of cuboidal or polygonal cells.(2) intercommunicating tubuloalveolar structure lined with two or more rows of cuboidal cells. (3) ductal structures composed of one or two rows of cuboidal cells.(4) occasional keratino cysts. (5)a matrix of varying compostion. ${ }^{3]}$ All these changes are seen in our case too. Headington recognized two types, apocrine and eccrine.[19] The apocrine type demonstrates irregular branching tubules (Tubulocystic pattern) lined by at least two cell-thick epithelium.

The eccrine type is characterized by rather uniform, small, round tubules that are evenly spaced within a myxoidchondroid matrix. Eosinophilic globules composed of collagen (So-called collagenous spherulosis) are rarely present and occasionally focal calcification can be seen. In few cases, the mesenchymal components shows plasmacytoid appearance due to peripheral displacement of the nuclei, which is called hyaline-cell rich chondroid syringoma. ${ }^{[20]}$ Histological features that suggest malignant transformation in a chondroid syringoma include cytologic atypia, infiltrative margin, satellite tumor nodule, tumor necrosis and involvement of deep structures.[21]

Total surgical excision is the treatment of choice for patients with benign chondroid syringoma. ${ }^{[6,11,14]}$ The risk of malignancy of this tumor is extremely rare, but it has been reported and therefore patients are recommended to have regular followup. ${ }^{[6,11,14]}$ Our patient was treated by complete surgical excision and sent the specimen for histopathology examination. Other modalities of treatment for small chondroid syringoma are electrodessication, dermabrasion, and vaporization with argon or $\mathrm{CO} 2$ laser have been used.[22] FNAC has been used for diagnostic purposes and many prove useful to determine pathology before excision; however, examination of excised tissue is most reliable in establishing a definitive diagnosis and to rule out malignancy. Because of the lobulated nature of the tumor, it is important to include a margin of normal tissue with the excision to ensure complete removal of the tumor, otherwise there are chances of local recurrence, hence careful follow-up is essential in cases where the tumor size is big as in our case. Patient had no recurrence within 6-month of follow- up.

\section{CONCLUSION}

Although a Giant chondroid syringoma is an uncommon tumor over cheek, it should be considered as one of the differential diagnosis, when dealing with tumors or nodules of this area. Because chondroid syringoma does not exhibit remarkable clinical manifestation, microscopic diagnosis is needed to facilitate adequate management. Regular follow-up of the chondroid syringoma, patient is recommended to evaluate the risk of local recurrence and malignancy.

\section{REFERENCES}

1. Lever WF, Schaumburg-Lever G. Tumors of the epidermal appendages in histopathology of the skin, 6th ed. Philadelphia, JB Lippincott, 1983;560-562.

2. Chen AH, Moreano EH, Houston B, et al. "Chondroid syringoma of the head and neck; clinical management and literature review," Ear, Nose and Throat Journal, vol. 75, no. 2, pp. 104-108, 1996.

3. Hirsch P and Helwig EB. "Chondroid syringoma-mixed tumor of skin, salivary gland type," Archives of dermatology, vol. 84, pp. 835-847, 1961.

4. Obaidat NA, Alsaad KO and Ghazarian D. "Skin adnexal neoplasms-part 2: an approach to tumors of cutaneous sweat glands." Journal of Clinical Pathology, vol. 60, no. 2, pp. 145-159, 2007.

5. Sivamani R, Wadhera A and Craig E. "Chondroid syringoma: case report and review of the literature." Dermatology Online Journal, vol. 12, no. 5, article no. 8, 2006.

6. Mebazaa A, Trabelsi S, Denguezli M, Sriha B, Belajouza C, Nouira R. Chondroid Syringoma of the arm: An unusual localization. Dermatol Online J 2006;12:14.

7. Poku JW, Sant GR and Ucci AA. "Chondroid syringoma of the scrotum." Journal of International Medical Research, vol. 24, no. 6, pp. 482-486, 1996.

8. Sheikh SS, Pennanen M and Montgomery E. "Benign chondroid syringoma: report of a case clinically mimicking a malignant neoplasm." Journal of Surgical Oncology, vol. 73, pp. 228-230, 2000.

9. Kumar B. Chondroid Syringoma diagnosed by fine needle aspiration cytology. Diagn Cytopathol 2010;38:38-40.

10. Paul K, Sreekar H, Dhanraj P, et al. Chondroid syringoma with extensive ossification. Ann Maxillofac Surg 2011;1:91-2.

11. Solanki LS, Dhingra M, Bhalla M, Thami GP, Punia RP, Batra S. Chondroid syringoma: Report of two cases in young patients. Dermatol Online J 2011;17:7.

12. Vasileiadis I, Kapetanakis S, Petousis A, et al. Rapidly growing chondroid syringoma of the external auditory canal: Report of a rare case. Case Rep Med 2011;2011:589-680.

13. Ramaswamy AS, Yenni VV, Wilfred C, et al. Hyaline cellrich chondroid syringoma of the finger. Indian J Dermatol 2011;56:217-9. 
14. Sirivella S, Gielchinsky I. Chondroid syringoma: A rare tumor of the chest wall. Ann Thorac Surg 2010;89:983-5.

15. Uyar B, Solak A, Sahin N, et al. Giant chondroid syringoma radiologically mimicking malignancy. Indian J Dermatol 2013;58:245.

16. Stout P and Gorman JG. "Mixed tumors of the skin of the salivary gland type." Cancer, vol. 12, pp. 537-543, 1959.

17. Hardisson D, Linares MD, Nistal M. Giant CS of the axilla. J Cutan Med Surg 1998;3:115-7.

18. Sungur N, Uysat A, Gumus M, et al. An unusual CS. Dermatol 1961;84:989-96.
19. Headington JT. "Mixed tumors of skin: Eccrine and apocrine types." Archives of dermatology, vol. 84, pp. 989-996, 1961.

20. Weedon D. Tumors of cutaneous appendages. IN: Weedon D, editor. Skin pathology. 2nd ed. Edinburgh:Churchill Livingstone;2002.p.881.

21. Bates AW, Basthun SI. Atypical mixed tumor of the skin: Histologic, immunohistochemical and ultrastructural features in three cases and a review of the criteria for malignancy. Am J Dermatopathol, 1998;20:35-40.

22. Agarwal A, Kumar A, Sinha AK, et al. Chondroid Syringoma. Singapore. Med J 2008;49:e33. 